\title{
Health-Related Quality of Life in Adults with Metabolic Syndrome: The Korea National Health and Nutrition Examination Survey, 2007-2008
}

\author{
Yu-Ji Lee ${ }^{a}$ Sook Young Woo ${ }^{b}$ Joong Hyun Ahn ${ }^{b}$ Seong Cho ${ }^{a}$ Sung Rok Kim ${ }^{a}$ \\ aDepartment of Medicine, Samsung Changwon Hospital, Sungkyunkwan University School of Medicine, \\ Changwon, and ${ }^{b}$ Biostatistics Team, Samsung Biomedical Research Institute, Seoul, Republic of Korea
}

\section{Key Words}

Metabolic syndrome $\cdot$ Quality of life $\cdot$ Obesity .

Comorbidity

\begin{abstract}
Background/Aims: An association between metabolic syndrome and impaired health-related quality of life (HRQoL) is still controversial. We investigated the association between metabolic syndrome in itself and HRQoL in the Korean adult population. Methods: The study is a cross-sectional analysis of 8,941 adults $\geq 19$ years of age who participated in the 2007 and 2008 Korean National Health and Nutrition Examination Survey. EuroQoL five-dimension (EQ-5D), the EQ-5D index and the EQ visual analogue scale (EQ VAS) were used to assess HRQoL. Results: The prevalence of metabolic syndrome was $26.2 \%$. Compared to the participants without metabolic syndrome, those with metabolic syndrome were older and comprised a higher proportion of men. Moreover, participants with metabolic syndrome were more likely to have a lower education level, to be current smokers, to have activity limitation and to have more frequent metabolic abnormalities and comorbidities. Metabolic syndrome was associated with HRQoL based on EQ-5D and EQ VAS in simple regression analysis. However, metabolic syndrome was not signifi-
\end{abstract}

cantly associated with HRQoL after adjusting for age, sex, smoking status, income, education level, marital status, obesity, diabetes mellitus, stroke, history of heart disease and chronic kidney disease for EQ-5D, and in addition history of depression for EQ VAS. Conclusion: Metabolic syndrome in itself was not associated with impaired HRQoL after adjusting for confounding variables such as socio-demographic factors, medical comorbidities and obesity.

Copyright $\odot 2012$ S. Karger AG, Basel

\section{Introduction}

Metabolic syndrome is a combination of abnormalities including abdominal obesity, high blood pressure (BP), dyslipidemia and impaired glucose metabolism [1]. People with metabolic syndrome have an increased risk of developing diabetes and cardiovascular disease [2]. In addition, metabolic syndrome has been associated with other adverse outcomes such as chronic kidney disease (CKD), fatty liver disease and Alzheimer disease [3-5]. Several components of metabolic syndrome and metabolic syndrome-related adverse events such as diabetes and cardiovascular disease have been associated with decreased health-related quality of life (HRQoL) [6-8]. Im-

\section{KARGER}

Fax +41613061234

E-Mail karger@karger.ch

www.karger.com
(C) 2012 S. Karger AG, Basel

$0250-6807 / 12 / 0614-0275 \$ 38.00 / 0$

Accessible online at:

www.karger.com/anm
Sung Rok Kim, MD, PhD

Department of Medicine, Samsung Changwon Hospital

Sungkyunkwan University School of Medicine, 50 Hapseong 2-dong

MasanHoiwon-Gu, Changwon 630-723 (Republic of Korea)

Tel. +82 55290 6332, E-Mail sungrok2.kim@samsung.com 
paired HRQoL has been associated with increased mortality and disease progression $[9,10]$. Although several studies have reported that metabolic syndrome is associated with impaired HRQoL [11-14], another study suggests that metabolic syndrome itself is not associated with impaired HRQoL [15]. Therefore, the impact of metabolic syndrome on HRQoL is less predictable and has not been clearly defined.

Obesity has been associated with the increase of various comorbidities, depression, worse physical functioning and a decreased HRQoL $[8,16,17]$. Thus, obesity may modify the relationship between metabolic syndrome and HRQoL. In Korea the prevalence of metabolic syndrome has been increased by significant socioeconomic and demographic changes and it has become an important public health problem. Here we assessed whether metabolic syndrome is associated with HRQoL regardless of medical comorbidities and obesity in the Korean adult population. We hypothesized that metabolic syndrome in itself would be associated with impaired HRQoL.

\section{Patients and Methods}

\section{Study Population}

The data were derived from the 2007 and 2008 Korean National Health and Nutrition Examination Survey (KNHANES), a population-based cross-sectional survey that was conducted with a stratified multistage sampling design according to age, gender and geographic area to select a representative sample of the civilian, noninstitutionalized Korean population. We used data from the health interview survey and medical examination. The health interview survey was completed by 8,941 adults aged 19 years and older. The response rates were 93.2\%. KNHANES was approved by the Korea Center for Disease Control and Prevention (KCDC) Institutional Review Board, and all participants signed a written informed consent form.

\section{Data Collection}

Trained interviewers interviewed participants face-to-face using a structured questionnaire. Participants were asked whether they had ever been told by a physician that they had hypertension, diabetes mellitus, stroke, heart disease, osteoporosis, osteoarthritis or depression. Participants were also asked whether they had a history of backache and took any medication for hypertension, diabetes mellitus or hyperlipidemia. Socio-demographic data were also collected, including age, sex, marital status, education, income, smoking status, alcohol consumption and activity limitation.

Anthropometric Measurement, Biochemical Parameters and Health-Related Quality of Life

Waist circumference was measured at the midpoint between the lowest rib and the iliac crest at minimal respiration. BP was measured three times at 30-second intervals and we used the mean of the three measured values for systolic and diastolic BP. Fasting venous blood from participants was sampled for measurements of plasma glucose, triglycerides and high-density lipoprotein cholesterol (HDL-C) by an ADVIA 1650 Chemistry Analyzer (Siemens, Deerfield, Ill., USA). Estimated glomerular filtration rate (eGFR) was calculated with the abbreviated modification of diet in renal disease equation, corrected to a body surface area of $1.73 \mathrm{~m}^{2}$, using the following equation for men:

\section{eGFR $\left(\mathrm{ml} / \mathrm{min} / 1.73 \mathrm{~m}^{2}\right)=$}

$186 \times$ serum creatinine $(\mathrm{mg} / \mathrm{dl})^{-1.154} \times$ age $^{-0.203}$.

For women, the result derived with the same formula was multiplied by 0.742 . Body mass index (BMI) was calculated as body weight $(\mathrm{kg})$ divided by the square meter of height.

The EuroQoL (EQ) instrument was used for evaluating HRQoL. EQ consists of the EQ five-dimension (EQ-5D) descriptive system and the EQ visual analogue scale (EQ VAS). The EQ$5 \mathrm{D}$ descriptive system is made up of the following five dimensions: mobility, self-care, usual activities, pain/discomfort and anxiety/depression. Participants are asked to select one of three levels (no problem, some problems and extreme problems) representing the most appropriate health state in each of the five dimensions. The EQ-5D is converted into a single summary index in which 1 indicates no problem in any of the five dimensions and zero indicates death. The EQ VAS records the participant's selfrated health on a vertical, visual analogue scale where a value of 0 means the 'worst imaginable health state' and a value of 100 means the 'best imaginable health state'. The Korean version of the EQ-5D had already been made and evaluated for its validity and reliability [18].

\section{Definition}

Obesity was defined as a BMI $\geq 25$. According to the National Cholesterol Education Program Adult Treatment Panel Guideline III [19] and central obesity criteria for Korean [20], participants who had three or more of the following criteria were considered to have the metabolic syndrome: (1) abdominal obesity (waist circumference $\geq 90 \mathrm{~cm}$ in men or $\geq 85 \mathrm{~cm}$ in women); (2) high triglycerides ( $\geq 150 \mathrm{mg} / \mathrm{dl}$ ) or drug treatment for elevated triglycerides; (3) low HDL-C ( $<40 \mathrm{mg} / \mathrm{dl}$ in men or $<50 \mathrm{mg} / \mathrm{dl}$ in women) or drug treatment for reduced HDL-C; (4) elevated fasting glucose $(\geq 100 \mathrm{mg} / \mathrm{dl})$ or drug treatment for elevated glucose, and (5) high BP (systolic BP $\geq 130 \mathrm{~mm} \mathrm{Hg}$ or diastolic BP $\geq 85 \mathrm{~mm}$ $\mathrm{Hg}$ ) or drug treatment for hypertension. CKD was defined as an eGFR of $<60 \mathrm{ml} / \mathrm{min} / 1.73 \mathrm{~m}^{2}$ or proteinuria by a dipstick urine analysis score of +1 or more.

\section{Statistical Analysis}

Data analyses were performed using the SAS software for survey analysis. The baseline data were presented as mean \pm standard error and percentage. Rao-Scott modified $\chi^{2}$ test for complex sampling design using PROC SURVEYFREQ in SAS was used to compare the frequency of comorbidities and categorical variables in participants with and without metabolic syndrome. Regression analysis for complex sampling design using PROC SURVEYREG in SAS was used to compare the mean value of continuous variables. We used linear regression for complex sampling design using PROC SURVEYLOGISTIC in SAS to evaluate the effect of metabolic syndrome on EQ-5D index and EQ VAS, adjusting for 
sex, age, smoking status, income, educational level, marital status, obesity, diabetes mellitus, stroke, history of heart disease and CKD for EQ-5D, and in addition history of depression for EQ VAS. $p$ values were corrected by Bonferroni's method due to multiple testing. We also used logistic regression analysis for complex sampling design implemented in PROC SURVEYLOGISTIC in SAS to evaluate the effect of metabolic syndrome on dimensions of EQ-5D after adjusting for sex, age, smoking status, income, educational level, marital status, obesity, diabetes mellitus, stroke, history of heart disease and CKD. p values and 95\% CIs for ORs were corrected by Bonferroni's method.

\section{Results}

The overall study sample was comprised of 6,107 nonobese participants and 2,834 obese participants. The prevalence of metabolic syndrome was $26.2 \%$. Of the nonobese and obese participants, 13.8 and $52.9 \%$ met criteria for metabolic syndrome, respectively. The socio-demographic characteristics of participants with and without metabolic syndrome are shown in table 1 . Compared to the participants without metabolic syndrome, those with metabolic syndrome were older $(52.8 \pm 0.40$ and $40.8 \pm 0.30$, respectively) and comprised a higher proportion of men ( 56.0 and $47.7 \%$, respectively). As expected, participants with metabolic syndrome had higher $\mathrm{BMI}$, serum glucose levels, BP and triglyceride levels, and lower HDL-C levels than those without metabolic syndrome. In addition, participants with metabolic syndrome were more likely to have a lower level of education, to be current smokers and to have activity limitation. Compared to participants without metabolic syndrome, those with metabolic syndrome had more frequent comorbid disorders, including stroke, angina or myocardial infarction, osteoporosis, osteoarthritis, lumbar pain and CKD. However, the prevalence of depression did not differ between participants with and without metabolic syndrome (12.68 and $11.01 \%$, respectively, $\mathrm{p}=0.055$ ).

The mean value of the EQ-5D index in participants with and without metabolic syndrome was 0.89 and 0.93 , respectively, which was statistically significant $(\mathrm{p}<$ 0.0001 ). The mean value of EQ VAS was 71.0 and 75.1, respectively, in participants with and without metabolic syndrome, which was also statistically significant $(\mathrm{p}<$ $0.0001)$. On simple linear regression, metabolic syndrome was significantly associated with the EQ-5D index (table 2). However, after adjusting for socio-demographic factors and medical comorbidities, including age, sex, smoking status, income, education level, marital status, obesity, diabetes mellitus, stroke, history of heart disease
Table 1. Baseline characteristics of nonobese participants with and without metabolic syndrome among KNHANES 2007-2008 participants $(\mathrm{n}=8,941)$

\begin{tabular}{|c|c|c|c|}
\hline & $\begin{array}{l}\text { Metabolic } \\
\text { syndrome } \\
\text { absent } \\
(\mathrm{n}=6,306)\end{array}$ & $\begin{array}{l}\text { Metabolic } \\
\text { syndrome } \\
\text { present } \\
(\mathrm{n}=2,635)\end{array}$ & $\begin{array}{l}\mathrm{p} \\
\text { value }\end{array}$ \\
\hline Sex male, $\%$ & 47.7 & 56.0 & $<0.0001$ \\
\hline Age, years & $40.8 \pm 0.30$ & $52.8 \pm 0.40$ & $<0.0001$ \\
\hline Current smoker, $\%$ & 25.7 & 29.1 & 0.0138 \\
\hline Marital status & & & $<0.0001$ \\
\hline Married, \% & 67.4 & 75.8 & \\
\hline $\begin{array}{l}\text { Other (single, separated, } \\
\text { widowed, divorced), \% }\end{array}$ & 32.6 & 24.2 & \\
\hline Education & & & $<0.0001$ \\
\hline High school and above, \% & 78.2 & 53.1 & \\
\hline Monthly income & & & 0.0403 \\
\hline USD 3,000 and more, $\%$ & 52.4 & 49.4 & \\
\hline Hypertension, \% & 6.9 & 39.0 & $<0.0001$ \\
\hline Diabetes, \% & 2.09 & 17.0 & $<0.0001$ \\
\hline Obesity, \% & 20.2 & 64.1 & $<0.0001$ \\
\hline BMI & $22.7 \pm 0.05$ & $26.1 \pm 0.08$ & $<0.0001$ \\
\hline Serum glucose, $\mathrm{mg} / \mathrm{dl}$ & $91.4 \pm 0.26$ & $110.4 \pm 0.75$ & $<0.0001$ \\
\hline $\mathrm{SBP}, \mathrm{mm} \mathrm{Hg}$ & $110.4 \pm 0.27$ & $126.2 \pm 0.49$ & $<0.0001$ \\
\hline $\mathrm{DBP}, \mathrm{mm} \mathrm{Hg}$ & $73.0 \pm 0.21$ & $81.4 \pm 0.28$ & $<0.0001$ \\
\hline Heart rate, beats per minute & $69.8 \pm 0.18$ & $70.8 \pm 0.28$ & 0.0001 \\
\hline Waist circumference, $\mathrm{cm}$ & $78.5 \pm 0.18$ & $89.9 \pm 0.21$ & $<0.0001$ \\
\hline Triglyceride, mg/dl & $105.1 \pm 1.10$ & $215.5 \pm 3.60$ & $<0.0001$ \\
\hline HDL-C, mg/dl & $51.3 \pm 0.37$ & $40.9 \pm 0.32$ & $<0.0001$ \\
\hline Activity limitation, $\%$ & 11.7 & 21.8 & $<0.0001$ \\
\hline Stroke, \% & 0.87 & 3.46 & $<0.0001$ \\
\hline \multicolumn{4}{|l|}{ Angina or } \\
\hline myocardial infarction, $\%$ & 1.16 & 3.70 & $<0.0001$ \\
\hline Osteoporosis, \% & 3.20 & 6.50 & $<0.0001$ \\
\hline Osteoarthritis, \% & 9.20 & 21.25 & $<0.0001$ \\
\hline Lumbar pain, $\%$ & 19.81 & 24.92 & $<0.0001$ \\
\hline Depression, \% & 11.01 & 12.68 & 0.0551 \\
\hline CKD, \% & 9.65 & 20.2 & $<0.0001$ \\
\hline EQ-5D & $0.93 \pm 0.002$ & $0.89 \pm 0.003$ & $<0.0001$ \\
\hline EQ VAS & $75.1 \pm 0.3$ & $71.0 \pm 0.5$ & $<0.0001$ \\
\hline
\end{tabular}

SBP $=$ Systolic BP; DBP = diastolic BP.

Table 2. Simple linear regression analysis to evaluate the associations between metabolic syndrome and HRQoL based on the EQ-5D index and EQ VAS

\begin{tabular}{lllll}
\hline & Estimate & SE & t value & p value \\
\hline $\begin{array}{l}\text { EQ-5D index } \\
\text { MS }\end{array}$ & -0.036 & 0.003 & -10.78 & $<0.0001$ \\
$\begin{array}{l}\text { EQ VAS } \\
\text { MS }\end{array}$ & -4.104 & 0.495 & -8.3 & $<0.0001$ \\
\hline
\end{tabular}

$\mathrm{SE}=$ Standard error; $\mathrm{MS}=$ metabolic syndrome. 
Table 3. Multiple linear regression analysis to evaluate the associations between metabolic syndrome and HRQoL based on the EQ-5D index and EQ VAS

\begin{tabular}{|c|c|c|c|c|c|c|c|c|c|}
\hline & \multicolumn{3}{|l|}{ Total } & \multicolumn{3}{|l|}{ Men } & \multicolumn{3}{|l|}{ Women } \\
\hline MS & 0.001 & 0.003 & 1.000 & 0.009 & 0.004 & 1.000 & -0.009 & 0.005 & 1.000 \\
\hline Abdominal obesity & 0.001 & 0.003 & 1.000 & 0.012 & 0.004 & 0.139 & -0.013 & 0.005 & 0.515 \\
\hline High BP & -0.002 & 0.003 & 1.000 & 0.003 & 0.003 & 1.000 & -0.009 & 0.005 & 1.000 \\
\hline Low HDL-C & 0.005 & 0.002 & 1.000 & 0.006 & 0.003 & 1.000 & 0.005 & 0.003 & 1.000 \\
\hline \multicolumn{10}{|l|}{ EQ VAS } \\
\hline MS & -1.282 & 0.549 & 0.123 & -1.454 & 0.613 & 0.222 & -1.029 & 0.937 & 1.000 \\
\hline Abdominal obesity & -1.714 & 0.566 & 0.016 & -1.842 & 0.708 & 0.118 & -1.400 & 0.854 & 1.000 \\
\hline High BP & -1.281 & 0.495 & 0.061 & -0.639 & 0.550 & 1.000 & -2.297 & 0.864 & 0.099 \\
\hline
\end{tabular}

p values were corrected by Bonferroni's method due to multiple testing. EQ-5D variables adjusted for age, sex, smoking status, income, educational level, marital status, obesity, diabetes mellitus, stroke, history of heart disease and CKD. EQ VAS variables adjusted additionally for depression. $\mathrm{SE}=$ Standard error; $\mathrm{MS}$ = metabolic syndrome; IFG = impaired fasting glucose .

and CKD, metabolic syndrome and its components, with the exception of high triglycerides, were not significantly associated with the EQ-5D index (table 3). When some/ extreme problems in dimensions of EQ-5D were used as cut-off points for determining impaired HRQoL, metabolic syndrome and its components were also not associated with EQ-5D dimensional problems in multiple logistic regression analysis (data not shown). Metabolic syndrome was significantly associated with EQ VAS in simple regression analysis (table 2). In a multiple linear regression analysis, metabolic syndrome and its components, with the exception of abdominal obesity and low HDL-C, were not significantly associated with EQ VAS after adjusting for age, sex, smoking status, income, education level, marital status, history of depression, obesity, diabetes mellitus, stroke, history of heart disease and CKD.

\section{Discussion}

The purpose of the present study was to determine the association between metabolic syndrome in itself in Korean adults and impaired HRQoL. We found that metabolic syndrome was not significantly associated with
HRQoL based on EQ-5D and EQ VAS after adjustments were made for confounding variables in this population. Metabolic syndrome was associated with definitive impairment of HRQoL based on EQ VAS after adjustments were made for only socio-demographic factors and obesity, even when $p$ values were corrected by Bonferroni's method due to multiple testing (data not shown; $\mathrm{p}=0.004$ ). However, interestingly, this relationship was not significant when adjustments were additionally made for medical comorbidities. This finding suggests that medical comorbidities that are increased in metabolic syndrome contribute to an increased risk of impaired HRQoL.

Previous reports have shown a significant association between metabolic syndrome and HRQoL [11-14]. However, in all of these reports, only socio-demographic factors such as age, sex, income, marital status, education, occupational status or smoking status were considered as confounding factors. It has been shown that insulin resistance, which plays a pivotal role in pathophysiology of the metabolic syndrome, is associated with impaired HRQoL [21]. Some reports have shown that hypertension may also be associated with decreased HRQoL and that dyslipidemia may be associated with a decline in physical functioning $[22,23]$. Obesity, which is a major risk factor for metabolic syndrome, is associated with insulin resis- 
tance, often leading to type 2 diabetes mellitus [24, 25]. Obesity increases the risk for various comorbidities including hypertension, dyslipidemia, cardiovascular disease, stroke and CKD, which are also associated with worse HRQoL [26-31]. Obesity also increases the incidence of osteoarthritis, which may have adverse effects on physical functioning $[32,33]$. Obese subjects may often be disadvantaged in education, employment and health care because of their size, and experience frequent depression, all of which can impair HRQoL $[8,16,17,34]$. Therefore, obesity could directly or indirectly have an effect on a variety of clinical implications related to metabolic syndrome. In the case of HRQoL, obesity may lead to the stronger association between metabolic syndrome and HRQoL. Therefore, we considered additional medical comorbidities and obesity as confounding variables to exclude the impact that these factors have on metabolic syndrome and HRQoL. As a result, in this study, metabolic syndrome was not significantly associated with HRQoL, which is in contrast with previous studies.

In Asian populations, the risk for metabolic abnormalities including diabetes, hypertension and dyslipidemia tend to increase even at a low BMI [35]. According to the recommended classifications for BMI adopted by the National Institute of Health and World Health Organization, obesity is BMI $\geq 30$ [36]. However, the definition of obesity varies by race. In Asians, a greater percentage of body fat is reached at a lower BMI than in other races. Therefore, for Asians, obesity is often defined as a $\mathrm{BMI} \geq 25$ [35]. In the present study it is reasonable to define obesity as $\mathrm{BMI} \geq 25$.
Of the five components that define metabolic syndrome, abdominal obesity and low HDL-C was associated with HRQoL based on EQ VAS. There are some reports that have shown the association of abdominal obesity with impaired HRQoL [37]. It seems that abdominal obesity affects impaired HRQoL differently compared to obesity based on BMI. Little seems to be known about the relationship between dyslipidemia and impaired HRQoL. A study has reported that dyslipidemia was associated with lower scores in the physical and psychological domains [38].

The limitation of this study is that the causal relationship between metabolic syndrome and HRQoL was not assessed owing to this being a cross-sectional study. However, the strengths of the study are that a large number of participants and representative population data were used to evaluate the association between metabolic syndrome and HRQoL.

In summary, metabolic syndrome was not associated with the impairment of HRQoL based on EQ-5D and EQ VAS after adjusting for confounding variables such as socio-demographic factors, medical comorbidities and obesity. The prevention and management of medical comorbidities may be important for improvement of HRQoL in adults with metabolic syndrome.

\section{Disclosure Statement}

There are no conflicts of interest.

\section{References}

1 Balkau B, Valensi P, Eschwege E, Slama G: A review of the metabolic syndrome. Diabetes Metab 2007;33:405-413.

$\checkmark 2$ Ford ES: Risks for all-cause mortality, cardiovascular disease, and diabetes associated with the metabolic syndrome: a summary of the evidence. Diabetes Care 2005;28:17691778 .

3 Marchesini G, Brizi M, Bianchi G, Tomassetti S, Bugianesi E, Lenzi M, McCullough AJ, Natale S, Forlani G, Melchionda N: Nonalcoholic fatty liver disease: a feature of the metabolic syndrome. Diabetes 2001;50: 1844-1850.

$\checkmark 4$ Razay G, Vreugdenhil A, Wilcock G: The metabolic syndrome and Alzheimer disease. Arch Neurol 2007;64:93-96.

$\checkmark 5$ Kurella M, Lo JC, Chertow GM: Metabolic syndrome and the risk for chronic kidney disease among nondiabetic adults. J Am Soc Nephrol 2005;16:2134-2140.
-6 Coffey JT, Brandle M, Zhou H, Marriott D, Burke R, Tabaei BP, Engelgau MM, Kaplan RM, Herman WH: Valuing health-related quality of life in diabetes. Diabetes Care 2002;25:2238-2243.

$>7$ Boini S, Briancon S, Guillemin F, Galan P, Hercberg S: Occurrence of coronary artery disease has an adverse impact on health-related quality of life: a longitudinal controlled study. Int J Cardiol 2006;113:215-222.

$\checkmark 8$ Han TS, Tijhuis MA, Lean ME, Seidell JC: Quality of life in relation to overweight and body fat distribution. Am J Public Health 1998;88:1814-1820.

$>9$ Kleefstra N, Landman GW, Houweling ST, Ubink-Veltmaat LJ, Logtenberg SJ, Meyboom-de Jong B, Coyne JC, Groenier KH, Bilo HJ: Prediction of mortality in type $2 \mathrm{di}$ abetes from health-related quality of life (ZODIAC-4). Diabetes Care 2008;31:932933.
10 Schenkeveld L, Pedersen SS, van Nierop JW, Lenzen MJ, de Jaegere PP, Serruys PW, van Domburg RT: Health-related quality of life and long-term mortality in patients treated with percutaneous coronary intervention. Am Heart J 2010;159:471-476.

-11 Miettola J, Niskanen LK, Viinamaki H, Sintonen H, Kumpusalo E: Metabolic syndrome is associated with impaired health-related quality of life: Lapinlahti 2005 study. Qual Life Res 2008;17:1055-1062.

12 Ford ES, Li C: Metabolic syndrome and health-related quality of life among US adults. Ann Epidemiol 2008;18:165-171.

13 Park SS, Yoon YS, Oh SW: Health-related quality of life in metabolic syndrome: the Korea National Health and Nutrition Examination Survey 2005. Diabetes Res Clin Pract 2011;91:381-388. 
14 Han JH, Park HS, Shin CI, Chang HM, Yun KE, Cho SH, Choi EY, Lee SY, Kim JH, Sung HN, Kim JH, Choi SI, Yoon YS, Lee ES, Song HR, Bae SC: Metabolic syndrome and quality of life (QOL) using generalised and obesity-specific QOL scales. Int J Clin Pract 2009; 63:735-741.

15 Vetter ML, Wadden TA, Lavenberg J, Moore RH, Volger S, Perez JL, Sarwer DB, Tsai AG: Relation of health-related quality of life to metabolic syndrome, obesity, depression and comorbid illnesses. Int J Obes (Lond) 2011;35:1087-1094.

16 Katz DA, McHorney CA, Atkinson RL: Impact of obesity on health-related quality of life in patients with chronic illness. J Gen Intern Med 2000;15:789-796.

-17 Roberts RE, Deleger S, Strawbridge WJ, Kaplan GA: Prospective association between obesity and depression: evidence from the Alameda County Study. Int J Obes Relat Metab Disord 2003;27:514-521.

$18 \mathrm{Kim} \mathrm{MH}$, Cho YS, Uhm WS, Kim S, Bae SC: Cross-cultural adaptation and validation of the Korean version of the EQ-5D in patients with rheumatic diseases. Qual Life Res 2005 14:1401-1406.

19 Grundy SM, Cleeman JI, Daniels SR, Donato KA, Eckel RH, Franklin BA, Gordon DJ, Krauss RM, Savage PJ, Smith SC Jr, Spertus JA, Costa F: Diagnosis and management of the metabolic syndrome: an American Heart Association/National Heart, Lung, and Blood Institute Scientific Statement - executive summary. Cardiol Rev 2005;13:322-327.

20 Lee SY, Park HS, Kim DJ, Han JH, Kim SM, Cho GJ, Kim DY, Kwon HS, Kim SR, Lee CB, Oh SJ, Park CY, Yoo HJ: Appropriate waist circumference cutoff points for central obesity in Korean adults. Diabetes Res Clin Pract 2007;75:72-80.
21 Schlotz W, Ambery P, Syddall HE, Crozier SR, Sayer AA, Cooper C, Phillips DI: Specific associations of insulin resistance with impaired health-related quality of life in the Hertfordshire Cohort Study. Qual Life Res 2007;16:429-436.

22 Lalonde L, O’Connor A, Joseph L, Grover SA: Health-related quality of life in cardiac patients with dyslipidemia and hypertension. Qual Life Res 2004;13:793-804.

23 Kumari M, Seeman T, Marmot M: Biological predictors of change in functioning in the Whitehall II study. Ann Epidemiol 2004;14: 250-257.

24 Park YW, Zhu S, Palaniappan L, Heshka S, Carnethon MR, Heymsfield SB: The metabolic syndrome: prevalence and associated risk factor findings in the US population from the third national health and nutrition examination survey, 1988-1994. Arch Intern Med 2003;163:427-436.

-25 Colditz GA, Willett WC, Rotnitzky A, Manson JE: Weight gain as a risk factor for clinical diabetes mellitus in women. Ann Intern Med 1995;122:481-486.

26 Lechleitner M: Obesity and the metabolic syndrome in the elderly - a mini-review. Gerontology 2008;54:253-259.

27 Huang Z, Willett WC, Manson JE, Rosner B, Stampfer MJ, Speizer FE, Colditz GA: Body weight, weight change, and risk for hypertension in women. Ann Intern Med 1998; 128:81-88.

28 Hubert HB, Feinleib M, McNamara PM, Castelli WP: Obesity as an independent risk factor for cardiovascular disease: a 26-year follow-up of participants in the Framingham Heart Study. Circulation 1983;67:968-977.

-29 Kramer H, Luke A, Bidani A, Cao G, Cooper R, McGee D: Obesity and prevalent and incident CKD: the Hypertension Detection and Follow-Up Program. Am J Kidney Dis 2005; 46:587-594.
30 Benzer W, Hofer S, Oldridge NB: Health-related quality of life in patients with coronary artery disease after different treatments for angina in routine clinical practice. Herz 2003;28:421-428.

- 31 Cerniauskaite M, Quintas R, Koutsogeorgou E, Meucci P, Sattin D, Leonardi M, Raggi A: Quality-of-life and disability in patients with stroke. Am J Phys Med Rehabil 2012;91:S3947.

32 Dixon JB: The effect of obesity on health outcomes. Mol Cell Endocrinol 2010;316:104108 .

33 Hart DJ, Spector TD: The relationship of obesity, fat distribution and osteoarthritis in women in the general population: the Chingford Study. J Rheumatol 1993;20:331-335.

34 Gortmaker SL, Must A, Perrin JM, Sobol AM, Dietz WH: Social and economic consequences of overweight in adolescence and young adulthood. N Engl J Med 1993;329: 1008-1012.

35 WHO Expert Consultation: Appropriate body-mass index for Asian populations and its implications for policy and intervention strategies. Lancet 2004;363:157-163.

36 National Institutes of Health: Clinical guidelines on the identification, evaluation, and treatment of overweight and obesity in adults - the evidence report. Obes Res 1998; 6(suppl 2):51S-209S

37 Rosmond R, Bjorntorp P: Quality of life, overweight, and body fat distribution in middle-aged men. Behav Med 2000;26:9094.

38 Martinelli LM, Mizutani BM, Mutti A, D’Elia MP, Coltro RS, Matsubara BB: Quality of life and its association with cardiovascular risk factors in a community health care program population. Clinics (Sao Paulo) 2008;63:783-788. 